\title{
Research on Current Situation and Countermeasures of Ecological Environment Construction of School Sports
}

\author{
$\mathrm{Bin} \mathrm{Xu}$ \\ College of Foreign Languages, Northeast Dianli University, Jilin, 132012, China
}

\begin{abstract}
The ecological environment of school sports is an environmental system which centers on the school physical education, and plays controlling and adjusting role in the emergence, existence and development of school sports. School ecological sport is an important part of ecological campus. It is also the inevitable tendency of modern civilization and development, and has extremely vital role to strengthen ecological construction of school sports. Based on the related concepts, $I$ bring to a discussion about how to carry on ecological construction of school sports, and put forward some related suggestions.
\end{abstract} school

Keywords-ecological sports; school sports; ecological

\section{INTRODUCTION}

From the ecological point of view, "Eco School" is a complex system which contributes to the interaction between the school education system and school ecological environment and carries on the energy flow, material cycle, information exchange and transfer. In 1996 December, the State Environmental Protection Administration, the Central Propaganda Department and the State Education Commission jointly promulgated the "national action program for environmental publicity and Education (1996-2010) outline". The outline poses that our nation would begin to embark on the establishment of the "green school", namely "ecological school" from 2000. The most remarkable characteristic of ecological school is its focus on the democracy, persistence and the common participation of all teachers and students, and ultimately makes the ecological environmental consciousness and behavior become the internal composition and the moral of the school life of teachers and students. "Eco School" advocated that the construction of school education environment, education objectives, curriculum design, and educational evaluation must contain ecological standards and environmental requirements.

\section{THE OBJECT AND METHOD OF STUDY}

\section{A. The research object}

The logical starting point of this study is the relevant review, the premise is combing for the basic theory of ecological sports, and the research object is based on the ecological environment construction of the latest domestic sports school.

\section{B. The research methods}

By using the method of literature, logical analysis, online search, journal search and analysis of relevant literature, the study explores the ecological environment construction of school sports in our country, and puts forward the countermeasures.

\section{THE RESULTS AND ANALYSIS}

\section{A. The ecological environment of school sports}

The ecological environment of school sports is a multidimensional space and a multiple environment which centers on the school physical education, and plays a controlling and adjusting role in the emergence, existence and development of school sports. It includes the natural ecological environment, social ecological environment and regulatory ecological environment.

1) The natural environment of Ecological School sports

The natural environment is the ecological conditions of human survival and development, is also the resources which human can know, utilize and then develop. It provides a suitable space and resources for the survival and development of human beings. The garden plan designed by the United States and Canada is to make full use of natural or semi natural ecological environment, and establish the education ecological system. The idea is to establish schools away from the smoky factories and crowded city place, with purpose of creating a vibrant and healthy environment to carry on tangible and intangible education. School sports is susceptible to the effects of various ecological factors in the natural environment, including the aim, function, content, form and method etc. without exception, affected the role and influence of ecological environment. The natural environment of School sports includes school buildings, sports building and lighting, athletic ability, sports venues, equipment and geographical factors. The natural ecological environment of school sports is the material basis for the survival and development of school physical education, produces the recessive effect on the implementation of school physical education, and plays the special role of environmental education ".

2) The social environment of Ecological school sports

Generally speaking, the social environment is unique to human living environment. The school social environment consists of various elements, including the 
political environment, economic environment, educational environment, family environment, population, environment, living environment and the school, class, interpersonal relationship, teaching atmosphere and so on. The whole society is a large ecosystem, the school is only one of a small ecological system, school sports, as part of school education, also influenced and restricted by various ecological factors in society in school, the specific ecological background. For example, the idea of lifelong physical education becoming an important guiding ideology of school physical education is closely related with the idea of lifelong education, and the concept of green Olympic Games also provide reference for ecological school sports.

3) The norm environment of ecological school sports

The norm environment refers to the attitudes, customs, temperament and concept which formed and kept in the human social life. [2] As far as its nature, the norm environment is unique to human society. It not only regulates the personal life and behavior, but also makes the personal spiritual to be occupied, makes the person's spirit life to be sublimed, so as to grasp the purpose of life and the meaning of life and to meet the needs of individual psychology. It makes a man to establish its value, practice morality and personality development in a regulated environment in the influence of others' expectations and requirements. The norm environment generally includes culture, art, science and technology, philosophy, morality, social convention, national traditions and customs, religion and so on; they will have a direct or indirect effect on school physical education.

\section{B. The current situation of ecology physical education at school}

1) The relative lack of sports facilities funding and reduction of space per student

Although the construction of sports facilities has been greatly improved in recent years, with the continuous surge in school enrolment, space per student decreased year by year. Data shows, in 1995, key colleges and universities in Sichuan Province outdoor space per student is about $9 \mathrm{~m} 2$, but the current percentage is less than $3 \mathrm{~m} 2$,

The maintenance fee of the school sports accounted the total funding for $1 \%$, but now it is down to less than $0.2 \%$. (3). Plastic and high-grade sports venues beauty our school, at the same time, closed management are forced to turn away more prospective students. 2.2.2 School sports ecology construction lags behind the other construction of ecological school

Sports construction is still far behind the construction of teaching building and library. The stadium is often the weakest zone of the school greening and beautifying. Sports venues are still in low level and poor quality. With dust flying in sunny day, mud filled in rainy day, serious site environmental pollution, sports facilities and equipment perennial disrepair and serious aging; large noise in movement, outstanding damage risks, students and teachers is difficult to carry out healthy teaching and activities outdoors, so that man and nature are difficult to reconcile and balance.

\section{2) Weak ecological concept}

Campus sport is a specific culture which belongs to the campus culture and sports culture. It is the sum of the spiritual culture, material culture and mode cultural shared by campus social group at this particular artificial environment, school. [4] However, weak ecological environmental awareness, lacking of physical and ecological norms, lacking of ecological sports culture, uncivilized phenomenon in the process of sports teaching and activities still exist, such as spitting, littering, smoking, picking flowers in sports field, deliberate destruction of sports facilities; inadequate sports field management, teaching environment and training environment of interference; pedestrians, bicycles, cars and other random accessing teaching sports field, students leaving a large number of stone, brick and white trash in the runway, airing the quilt, clothes in a single, parallel bars and other outdoor fitness equipment the court, and so on. The sub-standard lighting brightness in the playground area or the failing in turning on the lights in time are all serious security risks, so that students lack of safety and environmental protection movement condition, and it is difficult to carry out humanistic movement. It directly affects the effective operation of the school sports ecosystem.

\section{3) Imperfect ecological sports curriculum}

Ecological sports course construction is the main channel of spreading ecological information, raising ecological environmental awareness. the curriculum should reflect the ecological theme, and make the ecological construction of physical education curriculum can promote and affect the whole school to form a new ecological management concept, improve the ecological level of Education (5). Curriculum is flexibility and always changes. Curriculum system can maintain the integrity of physical knowledge, and also satisfy the students' needs of different methods of sports, fitness and leisure entertainment. According to the General Administration of Sport Scientific Research National Institute of science and technology development center Zhang Rudong' Statistics (6), about 76\% students like ball games, 6\% students like track and field sports, $18 \%$ students like swimming, hiking, sports dance and other sports activities, and China's traditional sports curriculum obviously can not meet the requirements of students.

\section{4) Serious Blindness}

The theory of ecological problems such as school sports concept, system is still not clear, the construction of school sports ecological curriculum is still relatively backward, and lacking program, plan, material, penetrated experiment and insufficient practical experience. Searching for relevant literature in computer, there are only more than 40 research articles concerning about the ecological school sports in recent 10 years. These research articles are only conducting surface research without 
depth, and have strong one-sidedness without comprehensive consideration about school. They seriously restrict the ecological development of school physical education.

\section{MEASURES TO STRENGTHEN THE CONSTRUCTION OF ECOLOGICAL SPORTS SCHOOL}

\section{A. Rational planning of campus environment, strengthening the construction of sports facilities}

First, we should adhere to the principle of overall planning, ecological priority, demonstration and popularization, bring the school sports ecological development into the overall planning of ecological schools, and formulate characteristic policies, objectives, steps based on actual situation; second, we should organize experts to do research jointly, strengthen the research on school ecology sports, formulate the evaluation index system and evaluation method of school ecological sports, implement the monitoring and management system of usual monitoring, occasional spot checking, regular assessing of schools, local government, regard the evaluation results as an important index of the evaluation of the school work, leadership performance. Third, we should integrate the school sports facilities and strengthen site utilization. Such as: the multi-use of field and facility, the clever collocation, the dispersion of large class (such as basketball, football) and small concentration (such as badminton, table tennis) to make full use of the site and teachers resources. Fourth, we should put the construction of ecological campus and ecological community together to integrate the ecological environment of school sports into the fast lane of ecological and harmonious development of society. Make sure the school sports facilities are open to the students, to serve the community, so as to ensure the good operation of the school ecological sports. Fifth, we should carry forward the spirit of innovation and speed up the construction of sports facilities. Such as, the construction of campus fitness path; the construction of campus rock climbing wall, orienteering and the expand of sports field, the creation of a water sports environment.

\section{B. Strengthening ecological construction of sports culture in schools}

The activities of the campus sports culture is an important content of most teachers and students after school life. It is important to actively carry out various kinds of sports cultural activities, so as to outstand school sports ecological culture atmosphere and to attract teachers and students to actively participate in the campus sports culture activities and ecological construction and rich their cultural activities and perfect themselves by doing these. First of all, we should widely publicize ecological sports knowledge and introduce domestic and foreign sports, fitness, sports health care method through radio, television, newspaper, and other warning signs. Second, based on the specific situation, we should make full use of school sports venues and teachers, adopt suitable method for the specific circumstances of the school, carry out rich and colorful sports activities and ecological sports cultural activities, enhance the grade of campus sports culture activities, and achieve maximum benefit of ecological sports school. Third, we should strengthen the construction of school sports teams, especially those who have both the mass basis and the characteristic feature, such as basketball teams, football teams. Fourth, we should strengthen humanities education, create a good campus sports culture atmosphere, make people accept the modern thought and culture in vivid sports practice. What's more, we ought to create a liberal, democratic and active physical education environment, so as to form the educational incentive mechanism of students' independent thinking, creative learning, and cultivate their ability and habit of independent thinking and self education, promote the comprehensive physical and mental development.

\section{Construction of ecological sports curriculum}

We should establish the thought of harmonious development between human, sports and nature, construct the ecological sports curriculum system, updating and restructure the teaching contents, establish ecological physical education, teaching plan, teaching material editing, with ecology as the main line, design new teaching methods and means, develop new product in ecological sports teaching activities in schools. In addition, we must strengthen the construction of teaching faculty; especially increase the introduction of teachers of roller skating, dance and other scarce project.

\section{Formulating and propagandizing the behavior norms of ecology sports, strengthening ecological moral construction}

We should propagandize the behavior norms of ecology sports, including norms of students' physical education, extra-curricular activities. Through the implementation of classroom, special activities, we will embody ecological ethics in various sports activities, and lead sports to a higher realm. For example, it is forbidden to wear leather shoes and unfit sports clothing or spit, wear topless in all kinds of sports on campus. We should keep field area clean, beverage bottle to the designated place, banning ; secondly, we should make the behavior criterion and safety system in field activity, for example, properly handling the waste, cherishing the flowers and plants and the wild animal in the forest, banning smoking; setting up warning signs in the sports venues etc..

\section{E. Attach importance to physical technology of green construction}

The construction of green technology is the various sports technology, products, means and measures centers on protecting human health and promoting the sustainable development of sports movement. We should strengthen the construction of sports of green technology, establish ecological standards for physical education, promote green technology, reduce pollution, protect the 
environment, respect for human nature, and promote the harmonious development of campus sports ecological environment and people's. we must increase investment in science and technology to help research and development of ecological sports equipment and products, and to improve the use rate of the product cycle.

\section{CONCLUSIONS}

School ecological sport is an important part of ecological campus. It is also the inevitable tendency of modern civilization and development, and has extremely vital role to strengthen ecological construction of school sports. It is able to provide a good environment for the school activities, at the same time; it also can cultivate students' sentiment, ecological concept and make them become the pillar of the future development of society.

\section{CORRESPONDING AUTHOR}

Bin Xu. College of Foreign Languages, Northeast Dian li University, Jilin, 132012, China.

\section{Email:34063479@qq.com.TEL:15843294007}

\section{REFERENCES}

[1] Zhang Ruifeng, Zuo Lin, Chen Kai. Establish the Ecological Consciousness and Strengthen Ecological Education of Physical Education Liaoning Sport. [J]Technology, 2006, 6 (28).

[2] Gong Jianlin. Thinking on Ecological Environment of School Sports in China .[J].The Physical Education Institute of Shanxi Normal University. Sinica, 2006, 6 (2): 66

[3] ZHAO HAIYAN, CAO XIULING. Construction of Ecological Campus Culture J.Shangdong Sports Science \& Technology, 2007, 12 (27): 4

[4] Deng Yuening. School Sports Ecology and Development Countermeasures of Journal of Chengdu Sport University. [J] 2004 (5): 30

[5] Cao Rongfang, Wang Lin. A Brief Study on the Teaching Function of the School Sports through Ecological Sports Curriculum [J] Education and occupation, 2006 (5).

[6] IIUXU. Considerations on Sports Environment Construction of ColLeges and Universities [J]Journal of Southwest Jiaotong University.(Social $\quad$ Sciences), 2007

(2). 